\title{
Pale and dark reddish melanic tawny owls differentially regulate the level of blood circulating POMC prohormone in relation to environmental conditions
}

\author{
Alexandre Roulin • Guillaume Emaresi • Pierre Bize • \\ Julien Gasparini · Romain Piault • Anne-Lyse Ducrest
}

Received: 16 June 2010 / Accepted: 21 February 2011 / Published online: 8 March 2011

(c) Springer-Verlag 2011

\begin{abstract}
Knowledge of the hormonal pathway controlling genotype-specific norms of reaction would shed light on the ecological factors to which each genotype is adapted. Environmentally mediated changes in the sign and magnitude of covariations between heritable melanin-based colouration and fitness components are frequent, revealing that extreme melanin-based phenotypes can display different physiological states depending on the environment. Yet, the hormonal mechanism underlying this phenomenon is poorly understood. One novel hypothesis proposes that these covariations stem from pleiotropic effects of the melanocortin system. Melanocortins are post-translationally modified bioactive peptides derived from the POMC prohormone that are involved in melanogenesis, anti-inflammation, energy homeostasis and stress responses. Thus, differential regulation of fitness components in relation to environmental factors by pale and dark melanic individuals may be due to colour-specific regulation of the POMC prohormone. Accordingly, we found that the degree of reddish melanic colouration was negatively correlated with blood circulating levels of the POMC prohormone in female tawny owls (Strix aluco) rearing a brood for which the size was experi-
\end{abstract}

\footnotetext{
A. Roulin $(\bowtie) \cdot$ G. Emaresi · P. Bize · J. Gasparini ·

R. Piault · A.-L. Ducrest

Department of Ecology and Evolution,

University of Lausanne, Lausanne, Switzerland

e-mail: Alexandre.Roulin@unil.ch

J. Gasparini

Laboratoire Ecologie et Evolution,

Université Pierre et Marie Curie,

CNRS UMR 7625, 75005 Paris, France

R. Piault

Animal Ecology Group, University of Groningen,

Kerklaan 30, 9751 NN Haren, The Netherlands
}

mentally reduced, but not when enlarged, and in females located in rich but not in poor territories. Our findings support the hypothesis that the widespread links between melanin-based colouration and fitness components may be mediated, at least in part, by the melanocortin system.

Keywords Melanin-based colouration - Melanocortin · Norms of reaction - Phenotypic plasticity $\cdot$ Pheomelanin . Proopiomelanocortin gene $\cdot$ Strix aluco

\section{Introduction}

Organisms usually experience temporal and spatial variation in environmental conditions. This phenomenon generates fluctuating selective pressures, potentially favouring different genotypes that vary in their phenotypic response to environmental changes, denoted norms of reaction or genotype by environment interaction (Hedrick 2006). Norms of reactions are shaped by key regulators such as hormones (e.g. sex steroids; Shahjahan et al. 2010) that are adjusted throughout the life cycle according to environmental conditions. Thus, our understanding of the proximate basis of reaction norms requires the measurement, along an environmental gradient, of candidate hormones.

In the present study, we adopt such an approach to investigate the proximate basis of the adaptive function of melanin-based colouration. We consider this phenotypic trait because the biochemistry of melanogenesis is well known (Sturm 2006). As for most multigenic phenotypic traits, several genes and hormones known to alter melanogenesis can explain inter-individual variation in colouration (e.g. 127 loci in mice; Silvers 1979; Bennett and Lamoreux 2003). Here, we focus only on one set of genes belonging to the melanocortin system. 
From a proximate perspective, the melanocortin system is involved in the regulation of multiple physiological functions, and may thus underlie covariations between melaninbased colouration and other phenotypic traits such as energy homeostasis, immunity, aggressiveness, sexual behaviour, resistance to oxidative stress and activation of the stress response and its further modulation (reviewed in Ducrest et al. 2008). Melanocortins are peptides derived from the proopiomelanocortin gene $(P O M C)$, which is translated to a POMC prohormone. This molecule undergoes a series of cell-specific proteolytic cleavages and modifications that result in the generation of several peptides, namely the melanocortins $(\alpha-, \beta$ - and $\gamma$-melanin-stimulating-hormones, MSH, and the adrenocorticotropic hormones, ACTH), and the endorphins (Pritchard et al. 2002). In vertebrates, the $P O M C$ gene is mainly expressed in the pituitary gland, but also in the central nervous system; in most peripheral tissues, neural and pituitaric melanocortins act as neurocrine and endocrine factors (Cone 2006), whereas peripherally produced melanocortins have paracrine and autocrine functions (Slominski et al. 2000).

Feather melanisation occurs during growth in chicks and moulting in adults. Melanin colouration is generated by the deposition of mixed eu- (brown/black to grey) and pheomelanin (yellow to reddish brown) pigments. In the first of three steps of melanogenesis, the rate-limiting enzyme tyrosinase oxidases L-tyrosine to produce dopaquinone that is further transformed to cysteinyldopa in the presence of cysteine derivatives. In a second step, pheomelanin is produced, and in the last stage when cysteine donors are depleted, eumelanin polymers are synthesised (Ito and Wakamatsu 2008). Therefore, the quantity and the ratio of eu- to pheomelanin depend primarily on the activity of tyrosinase and the presence of substrates cysteine and tyrosine in the melanosomes. Two major regulators of melanogenesis, namely the melanocortins and the Agouti protein (ASIP), control the level and activity of the tyrosinase via binding to the melanocortin 1 receptor (MC1R) (Ito and Wakamatsu 2011; Walker and Gunn 2010). Binding of melanocortins, particularly $\alpha-\mathrm{MSH}$, to $\mathrm{MC} 1 \mathrm{R}$, induces transcription and activity of eumelanic genes such as MITF, tyrosinase, TRP1 and DCT, and therefore increases the production of black/brown eumelanin. In contrast, the inverse-agonist/antagonist ASIP blocks the transcription of eumelanic genes (Le Pape et al. 2009) and hence switches the balance between eumelanogenesis towards pheomelanogenesis (Lin and Fisher 2007).

The different melanocortin peptides not only bind the MC1R but four other melanocortin receptors that regulate morphological, physiological and behavioural traits. Because of the numerous pleiotropic effects of the POMC gene, we predict an association between the different traits regulated by the melanocortins binding to the different MCRs (Ducrest et al. 2008). Hence, in species in which melanocortins account for part of the inter-individual variation in colouration, eumelanin- and pheomelanin-based colouration may be correlated positively and negatively, respectively, with the levels of the POMC prohormone and the levels of melanocortins that bind to MC2-5Rs.

Interestingly, recent studies have shown that covariations between the degree of melanic colouration and other phenotypic traits are more easily detected under specific environmental conditions (Roulin et al. 2008a; Piault et al. 2009; Roulin 2009). In the tawny owl (Strix aluco), for instance, we found that nestlings produced by pale and dark reddish melanic females have different reaction norms. Among nestlings raised by foster parents, nestlings born from dark reddish mothers grew faster than those born from paler reddish mothers when brood size was experimentally reduced, but not when it was experimentally enlarged, with dark and pale individuals growing at similar rates (Roulin et al. 2008a). Thus, in the tawny owl, the genetic correlation between melanic colouration and offspring growth was stronger in some environments than in others. Because in the tawny owl the expression of reddish melanism is strongly heritable and not or weakly condition-dependent (Gasparini et al. 2009a), this observation is likely to be the result of the action of some genes involved in growth trajectories and for which offspring born from differently coloured mothers should display either distinct alleles or different expression levels in relation to rearing conditions.

To test whether regulation of the POMC prohormone is colour-specific, we performed a brood size manipulation experiment in breeding female tawny owls (i.e. these females raised a brood for which we either added or removed one hatchling) in order to induce changes in the level of parental workload and thus modify the level of stress experienced by parents. Assuming that melanocortin hormones mediate colour-specific growth patterns found in previous experiments (Roulin et al. 2008a; Piault et al. 2009), we measured the levels of blood circulating POMC prohormone (Barna et al. 1998; Bell et al. 2005; Myers et al. 2005) in these breeding females. We thus investigated whether the levels of the POMC prohormone covary with the degree of reddish melanic colouration differentially in females rearing an experimentally reduced or enlarged brood. Interestingly, beechnut (Fagus sylvatica) production was particularly pronounced (personal observation), a food source for woodmice (Apodemus sp.) and bank voles (Clethrionomys glareolus) (Abt and Bock 1998; Margaletic et al. 2005), the staple prey species in the study area (Roulin et al. 2008b). Thus, beechnut densities should be proportional to prey densities. As a consequence, we examined whether the levels of the POMC prohormone covaries with the degree of reddish colouration differently in females rearing a progeny located in rich and poor territories with respect to beech density. 
The present study is a first step towards the understanding of the potential role played by melanocortins in generating reaction norms. Significant results should stimulate more detailed studies on the pleiotropic effects of the melanocortin system, its importance in generating covariations between melanin-based colouration and other phenotypic traits, and more generally why environmental heterogeneity can promote the evolution of local adaptation (Kawecki and Ebert 2004). Our aim is therefore not to test whether interindividual variation in reddish colouration is the result of the melanocortin system, but whether differently coloured owls differentially regulate the POMC prohormone in relation to environmental factors.

\section{Materials and methods}

The study was carried out in 2007 in western Switzerland, where we installed 366 nest boxes in forests located within a $911-\mathrm{km}^{2}$ area, at a mean altitude of $672 \mathrm{~m}$ (range 458$947 \mathrm{~m}$ ). Nest boxes were hung up on trees in forest patches of at least $4,000 \mathrm{~m}^{2}$; the mean distance between two nest boxes was $627 \mathrm{~m}$ with a minimal distance of $500 \mathrm{~m}$. The landscape consists of managed forests $(26.6 \%)$ and farmland $(55.5 \%)$, with 116 villages of $100-1,000$ inhabitants dispersed on the whole area. Forest patches ranged from 0.0038 to $32 \mathrm{~km}^{2}$ and were composed mainly of beeches followed by oaks (Quercus spp.), pure spruce (Picea abies), European silver fir (Abies alba) and common ash (Fraxinus excelsior). Farmlands consist mainly in cereal fields, pastures, truck farming, fruit orchards and fallows. In 2007, the 54 breeding females for which we measured levels of the POMC prohormone laid between 2 and 7 eggs (mean \pm SD $4.8 \pm 1.0$ ) from 1 February to 8 March (mean \pm SD 24 February \pm 7 days). Ninety-one percent of the eggs hatched and 1-7 nestlings per nest took their first flight (mean $\pm \mathrm{SD} 4.2 \pm 1.4$ ). Nestlings grow rapidly and leave their nest at 25-30 days of age (Galeotti 2001).

\section{Measurement of reddish colouration}

For each breeding female, we collected three feathers located on their back $5 \mathrm{~cm}$ below the neck. Feathers were then stuck with adhesive tape onto a black paper, placed in a black box equipped with a fluorescent tube (8w/20-640 blsuper), and individually photographed with a digital camera (Dimage A200, Konika Minolta) fixed at a distance of $27 \mathrm{~cm}$ to the feather. Pictures were imported in the software Adobe Photoshop to measure individual spectral hues, saturation and brightness. For each individual, we calculated a mean value over the three feathers and then extracted the first component (PCA1) of a principal components analysis, which explained $72 \%$ of the total variance. We multiplied
PCA1 values with -1 to obtain a scale from pale to dark reddish, a methodology that we did not use in previous papers. Measurements of colouration (i.e. PCA1) were shown to be repeatable, and strongly correlated with colour scores obtained with a spectrophotometer, and colour morph estimated in the field (Pearson's correlation $r=0.80, n=54$, $P<0.0001)$. The concentration of pheomelanin pigments stored in feathers accounts for $68 \%$ of the total variance in reddish colouration and eumelanin pigment concentrations for only 21\% (Gasparini et al. 2009a). Additional analyses based on the data collected by Gasparini et al. (2009a) showed that the ratio of pheomelanin/eumelanin feather content and the total amount of melanins contained in feathers are associated with PCA1 $(r=0.57, n=15, P=0.027$ and $r=0.87, n=15, P<0.0001$, respectively).

\section{Experimental procedure}

In 2007, we matched 90 nests in pairs with similar hatching date (Pearson's correlation, $P<0.0001$ ) and manipulated brood sizes by exchanging hatchlings between nests of the same pair; we took on average 2.4 nestlings from a nest $\mathrm{E}$ (enlarged) and brought them in another nest R (reduced) where we took on average 3.4 hatchlings to be brought in nest E. Each family was thus composed of nestlings from two origins with half the nests being experimentally enlarged by one nestling and the other half experimentally reduced by one nestling. Out of the 90 initial nests, we were able to collect a blood sample to measure POMC prohormone in adult females in 27 of the reduced nests and 27 of the enlarged nests. Age of the offspring when their mother was blood sampled did not differ between the two treatments (14 \pm 3.7 days, range 9-21; Student's $t$ test: $\left.t_{52}=1.19, P=0.24\right)$. Clutch size of enlarged and reduced nests was similar $\left(t_{52}=0.70, P=0.49\right)$. Breeding females from the two brood size treatments did not differ in wing, tail and tarsus lengths, body mass at the time of blood sampling and plumage colouration (Student's $t$ tests, $P$ values $>0.30$ ). Within pairs of experimental nests foster and biological mothers did not significantly resemble each other with respect to reddish colouration $(r=-0.13, n=35$, $P=0.46)$ and pairing with respect to colouration was not significantly disassortative in both the reduced and enlarged brood size treatment (Pearson's correlation comparing colouration of female and male partners: $r=-0.13, n=27$, $P=0.53$ vs. $r=-0.09, n=27, P=0.67$ ). We successfully created broods with a different number of nestlings as, at the time when we blood sampled breeding females, their nest contained significantly more nestlings in the enlarged than reduced treatment (mean \pm SE $4.9 \pm 0.2$ vs. $3.6 \pm$ 0.2 ; Student's $t$ test: $t_{52}=3.88, P=0.0002$ ). To investigate the long-term effect of the brood size manipulation experiment, we captured breeding individuals in 2008 and 
examined whether females rearing an enlarged brood in 2007 were less likely to breed in 2008 than females rearing a reduced brood in 2007.

Because beechnut production was very high in the autumn 2006, we recorded the proportion of beech trees during the winter 2006-2007, walking $75 \mathrm{~m}$ in the four cardinal points around each nest box. This proportion (mean is $32 \%$, range $0-92 \%$ ) was $\log _{10}+1$ transformed to obtain a normal distribution. In 2007, owls bred earlier in forests where beeches were more abundant $(r=-0.25, n=95$, $P=0.015$ ) indicating that abundance in beeches is an appropriate surrogate of some aspects of territory quality in the study year. The proportion of beech trees in territories of experimentally enlarged and reduced broods was similar $(P=0.17)$. Within each brood size treatment, female plumage colouration was not significantly correlated with female body size (i.e. wing, tail, tarsus and mass) and nestling age when females were blood sampled (Pearson's correlations, $P$ values $>0.18$ ) nor with the proportion of beeches (ANCOVA, colour: $F_{1,50}=0.95, P=0.33$; treatment: $F_{1,50}=2.21, P=0.14$; interaction: $F_{1,50}=2.90, P=0.10$ ).

\section{Assessment of blood circulating levels of the POMC} prohormone

Blood sample of each of the 54 breeding females was collected in tubes containing EDTA, immediately centrifuged to separate the plasma from the blood cells, and frozen in liquid nitrogen in the field until placed on the same day in the laboratory at $-80^{\circ} \mathrm{C}$. We quantified the amount of blood circulating POMC prohormone using the human OCTEIA POMC ELISA kit (IDS, Boldon, UK). We carried out the analyses using $50 \mu \mathrm{l}$ of plasma. This kit consists of a sandwich assay using two antibodies, which bind to POMC prohormone accordingly to its relative concentration. The sensitivity of the assay is $8 \mathrm{pmol} / \mathrm{l}$, the inter-assay precision is $10 \%$ and the cross-reactivity for ACTH is $3.6 \%$ and for $\alpha$-MSH $2.2 \%$. We box-cox transformed POMC prohormone values to normalize the dataset. POMC prohormone levels were not correlated with time of the day when blood samples were collected (mean is 1245 hours; range 0745 and 1745 hours) $(r=0.04, n=54, P=0.79)$, the time taken between capture and blood sampling (mean is $3.2 \mathrm{~min}$; range 0.1 and $4.3 \mathrm{~min} ; r=0.10, n=54, P=0.49$ ) and nestling age $(r=-0.12, n=54, P=0.37)$. These variables were therefore not considered in further analyses. In six females and one male, we collected two blood samples on two occasions. POMC prohoromone levels measured on these two occasions were strongly correlated $(r=0.82$, $n=7, P=0.025$ ). To avoid pseudo-replication, we calculated mean values over the two measurements. Finally, it is worth noting that the level of POMC prohormone we measured is not the amount of melanocortins directly involved in melanogenesis, since the feathers collected for colour assessment were not growing anymore.

\section{Statistics}

We performed statistical analyses using JMP IN 7.0.0. We used a stepwise ANCOVA including the box-cox transformed levels of POMC prohormone as the dependent variable, and brood size treatment ('treatment'), proportion of trees that were beeches ('beeches') and reddish colouration measured as PCA1 ('colour') as three independent variables, plus all possible interactions. Non-significant interactions were subsequently removed from the final model. The analyses are two-tailed and significance level is set to 0.05 . In all models, residuals were normally distributed, and variances were homogeneous between treatments.

\section{Results}

The brood size manipulation experiment had the intended effect on breeding females. Of the 27 females rearing an experimentally enlarged brood in 2007, only $8(29.6 \%)$ of them were breeding in 2008, whereas 16 out of $27(59.3 \%)$ females rearing an experimentally reduced brood in 2007 were breeding in 2008 (Chi-square test: $\chi^{2}=4.80$, $P=0.028)$.

Mean concentration in the POMC prohormone was $68.5 \mathrm{pmol} / \mathrm{l}$ (SD 85.4; range 6 and 346.7). After stepwise backward simplification of the model, the interactions 'treatment' by 'colour' and 'beeches' by 'colour' were both significant (Table 1). When brood size was experimentally reduced, darker reddish females showed lower levels in the POMC prohormone than pale reddish females (multiple

Table 1 Analysis of covariance testing POMC prohormone levels (box-cox transformed) in relation to brood size manipulation experiment and the proportion of trees that were beeches (an index of food abundance) in breeding female tawny owls (Strix aluco)

\begin{tabular}{llll}
\hline Source of variation & \multicolumn{2}{l}{ Test statistics } & \multirow{2}{l}{$P$} \\
\cline { 2 - 3 } & $F$ & $d f$ & \\
\hline Colour & 2.00 & 1,48 & 0.16 \\
Treatment & 0.09 & 1,48 & 0.84 \\
Beeches & 0.11 & 1,48 & 0.74 \\
Colour $\times$ beeches & 4.48 & 1,48 & 0.039 \\
Colour $\times$ treatment & 4.80 & 1,48 & 0.033
\end{tabular}

The term colour refers to the degree of reddish colouration, treatment to the brood size manipulation experiment (enlarged vs. reduced broods), and beeches to the proportion of trees that were beeches in forests where nest boxes were erected. We removed from the final model the triple interactions and the two-way interaction 'treatment $\times$ beeches' which were not significant $(P$ values $>0.40)$ 


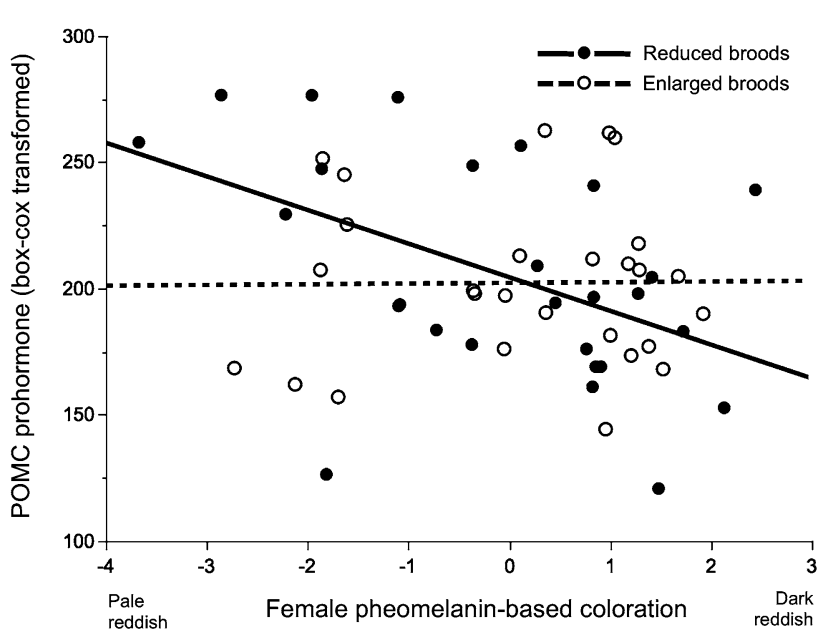

Fig. 1 Relationship between POMC prohormone levels (box-cox transformed) in relation to reddish colouration in breeding female tawny owls (Strix aluco) raising an experimentally reduced (closed circles and straight regression line; $r=-0.48, n=27, P=0.012$ ) or enlarged brood (open circles and broken regression line; $r=0.01, n=27$, $P=0.95)$

regression analysis, colour: $F_{1,24}=4.90, P=0.037$; beech: $F_{1,24}=0.51, P=0.48$ ), whereas there was no relationship between colouration and levels of the POMC prohormone in the enlarged treatment (multiple regression analysis, colour: $F_{1,24}=0.02, P=0.88$; beech: $F_{1,24}=0.99, P=0.33$ ) (Fig. 1). The interaction 'beeches' by 'colour' was significant because darker reddish females had lower levels of the POMC prohormone when their territory was located in a forest where beeches were abundant (territories with proportion of beeches above the median, ANCOVA, colour as covariate: $F_{1,25}=5.57, P=0.026$; treatment as factor: $F_{1,25}=0.12, P=0.73$ ) but not when relatively rare (territories with proportion of beeches below the median, ANCOVA, colour as covariate: $F_{1,23}=0.03, P=0.87$; treatment as factor: $F_{1,23}=0.37, P=0.55$ ).

\section{Discussion}

The $P O M C$ gene is mainly expressed in the pituitary gland and also in the brain and in peripheral tissues. The POMC mRNA is translated to the POMC prohormone, which through tissue-specific processing results in the different melanocortins ( $\alpha-, \beta$-, and $\gamma-\mathrm{MSH}$ and ACTH, as well as $\alpha-, \beta$-, and $\gamma$-endorphins) that exert neurocrine, endocrine and paracrine actions (Pritchard et al. 2002; Boswell and Takeuchi 2005). Because these different melanocortins are able to bind to five distinct melanocortin receptors (MC15Rs), controlling melanogenesis but also behavioural and physiological traits, Ducrest et al. (2008) recently proposed the hypothesis that the melanocortin system generates phenotypic correlations between melanin-based colouration and other attributes. This hypothesis assumes that the level of melanocortin activity in one tissue is proportional to activity in other tissues. Connections between the different tissues, particularly between the pituitary and the skin, may exist through endocrine and neurocrine circuits. Homozygous knockout mice for Tpit (a Tbox transcription factor) that is restrictively expressed and regulates the pituitary development, used as a model for isolated ACTH defect, exhibit a yellowish belly (Pulichino et al. 2003) as in POMC KO mice (Yaswen et al. 1999) and POMC-deficient human (Krude et al. 1998). This suggests that in mice pituitaric $\alpha$-MSH circulates in the blood stream and regulates melanogenesis in skin. Based on this kind of observation, we predict that the baseline level of circulating POMC prohormone may be correlated with the baseline activity of the melanocortin bioactive peptides that regulate the degree of melanin-based colouration.

We found that darker reddish female tawny owls had lower levels of the POMC prohormone than paler reddish females when rearing an experimentally reduced (but not enlarged) brood and when they were located in forests where the proportion of beech trees was high (but not when low), an indirect measure of the abundance of their staple prey. In the following, we discuss the potential physiological effects of circulating POMC prohormone, why the levels of circulating POMC prohormone can be associated with colouration in prime environments, whether covariation between colouration and levels of POMC prohormone is adaptive, and how future studies should proceed.

\section{Potential physiological effects of the circulating POMC prohormone}

The level of the circulating POMC prohormone in the tawny owl was $68.5 \mathrm{pmol} / \mathrm{l}$ (range 6-346.7), a value of similar order of magnitude to the values reported in dogs (range 15-108 pmol/l) and sheep (40-75 pmol/l) using the same assay (Granger 2004; Bell et al. 2005). To investigate the physiological effects of circulating melanocortins, researchers administrated these hormones or their analogues orally, subcutaneously, intraperitoneally, intravenously or intracerebrally. Systemic injection of melanocortins resulted in the darkening of skin (Lerner and McGuire 1979; Ugwu et al. 1997), in a reduction of inflammatory reactions, septic shock and fever (Chiao et al. 1996; Gonindard et al. 1996; Grabbe et al. 1996; Huang et al. 1998; Getting 2006) as well as stress-induced corticosterone levels (Daynes et al. 1987), and an increase in sexual behaviour (van der Ploeg et al. 2002; Wessells et al. 2003) and aggressiveness (Morgan and Cone 2006). As indicated above, melanocortin peptides control many important physiological pathways, suggesting that these active peptides should be tightly regulated at the levels of their activity 
(acetylation, amidation, phosphorylation), their processing by convertases (PC1, PC2, carboxypeptidase E, PAM) (Wilkinson 2006), and expression of the POMC prohormone.

Proximate mechanisms underlying covariation between the levels of blood circulating POMC prohormone, colouration and stress

Melanin pigments account for a large part of the variation in animal colouration. The synthesis of melanin is controlled, in part, by melanocortins produced and processed in the skin (paracrine and autocrine) (Slominski et al. 2000; Rousseau et al. 2007; Schallreuter et al. 2008). Endocrine melanocortin control of colouration cannot be excluded, since stress stimulates a release of plasma POMC-derived polypeptides in man (Meyerhoff et al. 1988), or increases plasma levels of $\alpha-\mathrm{MSH}$ and ACTH and further induces skin darkening in the arctic charr (Salvelinus alpinus; Hoglund et al. 2000). Moreover, mice deficient for Tpit, a transcription factor that regulates pituitary development, exhibit a yellowish belly fur (Pulichino et al. 2003).

Since melanocortins are involved in the control of important physiological pathways such as stress control via the hypothalamic-pituitary-adrenocortical axis (HPA) through the action of $\mathrm{ACTH}$, which is derived from the POMC prohormone, it is expected that POMC expression and in turn the POMC prohormone are environmentally regulated. Accordingly, stress induced through a week of immobilization induced an increase in pituitaric POMC mRNA, plasma ACTH and corticosterone in rats (Noguchi et al. 2006). In near-term ovine fetus, long-term hypoxia increased plasma POMC prohormone and ACTH but reduced the ratio of POMC prohormone to ACTH compared to control sheep (Myers et al. 2005).

In tawny owls, pale reddish females decreased their level of plasma POMC prohormone when experiencing a higher level of stress (i.e. experimentally enlarged broods), whereas dark reddish females produced POMC prohormone independently of the brood size manipulation treatment. Different scenarios can account for this observation. Firstly it is possible that, as shown by Myers et al. (2005), under stressful conditions more ACTH is necessary and more plasma POMC prohormone is processed to ACTH resulting in a reduction of plasma POMC prohormone in pale reddish owls. Secondly, certain stress such as fasting induces a reduction in pituitaric POMC mRNA. Experiments carried out in laboratory animals showed that fasting usually induces a decrease in the expression of the POMC gene (Sanchez et al. 2004; Myers et al. 2005; Dallman et al. 1999; Bertile et al. 2003; Schwartz and Porte 2005). Accordingly, pale pheomelanic females may decrease the level of POMC gene expression because melanocortins may induce too many costly activities, which would be detrimental when resources are scarce.

Another scenario is based on the assumption that the POMC prohormone and ACTH levels needed under stressful conditions are colour-specific, with differently coloured individuals requiring different amount of ACTH to withstand a stressful situation, as shown for feeding behaviour in different rat strains, where fasting reduces hypothalamic POMC mRNA in Brown Norway rats and induces POMC mRNA in Fisher rats (Kappeler et al. 2004). As different sources of stress induce an increased or reduced expression level of the POMC gene (Noguchi et al. 2006; Chen et al. 2008), pale reddish individuals had lower levels of POMC prohormone under stressful conditions, i.e. when rearing an enlarged brood compared to when rearing a reduced brood (Fig. 1), and dark reddish females may increase POMC prohormone levels under stressful conditions.

Studies on the proximate mechanisms occurring under stressful conditions are rapidly expanding but little is known about spatial and temporal variation in $P O M C$ gene expression, $\mathrm{PC} 1 / 2$ activation and $\mathrm{ACTH}$ and $\alpha$-MSH levels between different colour morphs, along an environmental gradient (e.g. different intensity and type of stress). However, these different scenarios stem from stronger covariations between colouration and the levels of the POMC prohormone under prime environmental conditions. A number of biochemical factors regulate $P O M C$ gene expression, translation and further processing and modification. Such factors include steroids, glucocorticoids, cytokines, prostaglandines, cathecholamine and other neurotransmitters (Schallreuter et al. 2008; Slominski et al. 2004), potentially allowing individuals to adjust melanocortin levels in relation to environmental or social factors but also to life stages (Ellis et al. 2008; Palermo et al. 2008). Knowledge of the identity of these factors, their effect on melanocortin levels and physiological traits, and of how they are themselves regulated is key to determining when individuals switch on/off the expression of the POMC gene.

Are life history strategies of dark and pale reddish tawny owls mediated by melanocortins?

From an ultimate point of view, why did the POMC prohormone circulate at higher levels in pale reddish owls raising a reduced compared to an enlarged brood? Furthermore, why did melanocortin precursors circulate in the blood stream at relatively constant levels in dark reddish owls, while in paler owls levels were more variable? A likely explanation is that the net benefit of circulating POMC prohormone is higher in situations of low than high stress, particularly in pale individuals. Given the numerous physiological effects of melanocortins, their overproduction 
may lead individuals to invest resources into a wide range of activities, which in turn could be detrimental under stressful conditions. Interestingly, even under weakly stressful situations, dark reddish birds also showed low levels of POMC prohormone suggesting that they avoid investing in too many activities regulated by melanocortins. Dark reddish individuals may thus invest resources in traits regulated by melanocortins relatively independently of changes in the environment, while pale conspecifics regulate these traits more finely in relation to variation in environmental factors. Accordingly, various studies showed that pale and dark reddish tawny owls invest resources differentially into various traits including body growth and maintenance, immunity and reproduction. Pale birds seem to adopt less risky strategies than dark conspecifics: when conditions are poor, they skip reproduction more often (Roulin et al. 2003), invest less effort in mounting a strong immune response following an immune challenge to limit body mass loss (Gasparini et al. 2009a, b), and produce nestlings that are better able to maintain body mass under low food supply (Piault et al. 2009). If pale individuals are better able to buffer variation in environmental factors by finely regulating melanocortin levels, dark reddish birds may have some other advantages such as offspring growing faster in body mass when prey are provided ad libitum (Roulin et al. 2008a, b; Piault et al. 2009), and when challenged with antigens, they maintain a stronger level of antibody for a longer period of time compared to pale individuals (Gasparini et al. 2009a).

\section{Conclusion and perspectives}

Melanin-based colouration is a multigenic trait and interindividual variation in the degree of melanism may be caused in part by melanocortins. Regardless of the exact role played by melanocortins in generating variation in colouration, our study demonstrates that differently melanic female tawny owls differentially regulate the POMC prohormone in relation to environmental factors. Because in the tawny owl the expression of reddish colouration is strongly heritable and not or weakly condition-dependent (Gasparini et al. 2009a), an environmentally induced change in the magnitude of the covariation between colouration and the levels of the POMC prohormone must be due to a change in the level of the POMC prohormone but not to a change in colouration.

The present study is a first step into an understanding of the potential role of hormones in generating norms of reaction (Boswell and Takeuchi 2005; Ducrest et al. 2008), and hence our reasoning goes beyond the melanocortin system. Knowledge of the regulators of phenotypic correlations is helpful to predict how their sign and magnitude can change along an environmental gradient. In this context, melaninbased colouration is a promising model system, and the present study raises a number of issues to tackle the ecological role of the melanocortin system. First, we intend to measure expression levels of the POMC gene in relation to colouration in several tissues. The idea is to investigate whether expression levels of this gene are coordinated across organs, which is plausible given that melanocytes have a neuroendocrine regulatory function (Slominski 2009). This is an important issue because melanin production is determined, in part only, by the expression of the POMC gene found in feather buds, whereas many phenotypic traits that covary with melanin-based colouration are influenced by $P O M C$ gene copies found in the pituitary gland that control for instance energy homeostasis (Coll et al. 2004). Second, our aim is to assess the levels of prohormone convertases (PC1/2) processing the POMC prohormone and the levels of the resulting melanocortin bioactive peptides, especially under the stress experienced with the brood size manipulation. The final step will be an experimental injection of melanocortins to confirm their role in generating inter-individual colour variation and to investigate whether they generate covariations between melaninbased colouration and other phenotypic traits. Furthermore, the inverse-agonist/antagonist agouti protein (ASIP) should also be considered in future studies as it may play another key role in the balance between pheo- and eumelanogenesis, and thus may determine colouration and regulation of many other traits (Ducrest et al. 2008). A thorough study of the melanocortin system should provide a proximate explanation as to how norms of reaction are regulated by differently melanic individuals, and help understand the adaptive function of variation in melanin-based colouration. It may also provide an appropriate system to tackle issues about genotype by environment interactions.

Acknowledgments We are grateful to Swiss National Science Foundation (grant no. PPOOA-102913 and 31003A_120517 to A.R.). We thank four anonymous referees and Pawel Koteja for useful comments on a previous version of the text.

\section{References}

Abt KF, Bock WF (1998) Seasonal variations in diet composition in farmland field mice Apodemus spp. and bank voles Clethrionomys glareolus. Acta Theoriol 43:379-389

Barna I, Koenig JI, Péczely P (1998) Characteristics of the proopiomelanocortin system in the outdoor-bred domestic gander. Gen Comp Endocrinol 109:44-51

Bell ME, McDonald TJ, Myers DA (2005) Proopiomelanocortin processing in the anterior pituitary of the ovine foetus after lesion of the hypothalamic paraventricular nucleus. Endocrinology 146:2665-2673

Bennett DC, Lamoreux ML (2003) The color loci of mice-a genetic century. Pigment Cell Res 16:333-344 
Bertile F, Oudart H, Criscuolo F, Le Maho Y, Raclot T (2003) Hypothalamic gene expression in long-term fasted rats: relationship with body fat. Biochem Biophys Res Comm 303:1106-1113

Boswell T, Takeuchi S (2005) Recent developments in our understanding of the avian melanocortin system: its involvement in the regulation of pigmentation and energy homeostasis. Peptides 26:1733-1743

Chen JX, Tang Y-T, Yang J-X (2008) Changes of glucocorticoid receptor and levels of CRF mRNA, POMC mRNA in brain of chronic immobilization stress rats. Cell Mol Neurobiol 28:237-244

Chiao H, Foster S, Lipton TR, Star RA (1996) Alpha-melanocyte-stimulating hormone reduces endotoxin-induced liver inflammation. J Clin Invest 97:2038-2044

Coll AP, Farooqi IS, Challis BG, Yeo GS, O'Rahilly S (2004) Proopiomelanocortin and energy balance: insights from human and murine genetics. J Clin Endocrinol Metab 89:2557-2562

Cone RD (2006) Studies on the physiological functions of the melanocortin system. Endocr Rev 27:736-749

Dallman MF, Akana SF, Bhatnagar S, Bell ME, Choi S, Chu A, Horsley C, Levin N, Meijer O, Soriano LR, Strack AM, Viau V (1999) Starvation: early signals, sensors, and sequelae. Endocrinology 140:4015-4023

Daynes RA, Robertson BA, Burnham DK, Newton R (1987) Alphamelanocyte-stimulating hormone exhibits target cell selectivity interleukin 1-inducible responses in vivo and in vitro. J Immunol 139:103-109

Ducrest A-L, Keller L, Roulin A (2008) Pleiotropy in the melanocortin system, colouration and behavioural syndromes. Trends Ecol Evol 23:502-510

Ellis C, Moar KM, Logie TJ, Ross AW, Morgan PJ, Mercer JG (2008) Diurnal profiles of hypothalamic energy balance gene expression with photoperiod manipulation in the Siberian hamster, Phodopus sungorus. Am J Physiol Regul Integr Comp Physiol 294:11481153

Galeotti P (2001) Tawny owl. BWP Update 3:43-77

Gasparini J, Bize P, Piault R, Wakamatsu K, Blount JD, Ducrest A-L, Roulin A (2009a) Strength and cost of mounting an immune response are associated with a heritable melanin-based color trait in female tawny owls. J Anim Ecol 78:608-616

Gasparini J, Piault R, Bize P, Roulin A (2009b) Synergetic and antagonistic interaction between different branches of the immune system is related to melanin-based colouration in nestling tawny owls. J Evol Biol 22:2348-2353

Getting SJ (2006) Targeting melanocortin receptors as potential novel therapeutics. Pharmacol Therapeut 111:1-15

Gonindard C, Goigoux C, Hollande E, D'Hinterland LD (1996) The administration of an alpha-MSH analogue reduces the serum release of IL-1 alpha and TNF alpha induced by the injection of a sublethal dose of lipopolysaccharides in the BALB/c mouse. Pigment Cell Res 9:148-153

Grabbe S, Bhardwaj RS, Mahnke K, Simon MM, Schwarz T, Luger TA (1996) Alpha-Melanocyte-stimulating hormone induces hapten-specific tolerance in mice. J Immunol 156:473-478

Granger N (2004) Plasma concentrations of adrenocorticotrophic hormone precursors in dogs with Cushing's disease: evaluation in the detetction of large pituitary adenoma. La Faculté de Médecine de Créteil, Ecole Nationale Vétérinaire d'Alfort 65

Hedrick PW (2006) Genetic polymorphism in heterogeneous environments: the age of genomics. Annu Rev Ecol Evol Syst 37:67-93

Hoglund E, Balm PHM, Winberg S (2000) Skin darkening, a potential social signal in subordinate arctic charr (Salvelinus alpinus): the regulatory role of brain monoamines and pro-opiomelanocortinderived peptides. J Exp Biol 203:1711-1721

Huang QH, Hruby VJ, Tatro JB (1998) Systemic alpha-MSH suppresses LPS fever via central melanocortin receptors independently of its suppression of corticosterone and IL-6 release. Am J Physiol Regul Integr Comp Physiol 275:524-530

Ito S, Wakamatsu (2008) Chemistry of mixed melanogenesis-pivotal roles of dopaquinone. Photochem Photobiol 84:582-592

Ito S, Wakamatsu K (2011) Human hair melanins: what we have learned and have not learned from mouse coat color pigmentation. Pigment Cell Melanoma Res (in press)

Kappeler L, Zizzari P, Grouselle D, Epelbaum J, Bluet-Pajot MT (2004) Plasma and hypothalamic peptide-hormone levels regulating somatotroph function and energy balance in fed and fasted states: a comparative study in four strains of rats. J Neuroendocrinol 16:980-988

Kawecki TJ, Ebert D (2004) Conceptual issues in local adaptation. Ecol Lett 7:1225-1241

Krude H, Biebermann H, Luck W, Horn R, Brabant G, Grüters A (1998) Severe early-onset obesity, adrenal insufficiency and red hair pigmentation caused by POMC mutations in humans. Nature Genet 19:155-157

Le Pape E, Passeron T, Giubellino A, Valencia JC, Wolber R, Hearing VJ (2009) Microarry analysis sheds light on the dedifferentiating role of agouti signal protein in murine melanocytes via the Mc1r. Proc Natl Acad Sci USA 106:1802-1807

Lerner AB, McGuire J (1979) Effect of alpha and beta melanocyte stimulating hormones on the skin color of man. Nature 189:176-179

Lin JY, Fisher DE (2007) Melanocyte biology and skin pigmentation. Nature 445:843-850

Margaletic J, Bozic M, Grubesic M, Glavas M, Bäumler W (2005) Distribution and abundance of small rodents in Croatian forests. J Pest Sci 78:99-103

Meyerhoff JL, Oleshansky MA, Mougey EH (1988) Psychologic stress increases plasma levels of prolactin, cortisol, and POMC-derived polypeptides in man. Psychosom Med 50:295-303

Morgan C, Cone RD (2006) Melanocortin-5 receptor deficiency in mice blocks a novel pathway influencing pheromone-induced aggression. Behav Genet 36:291-300

Myers DA, Bell PA, Hyatt K, Mlynarczyk M, Ducsay CA (2005) Long term hypoxia enhances proopiomelanocortin processing in the near-term ovine fetus. Am J Physiol Regul Integr Comp Physiol 288:R1178-R1184

Noguchi T, Makino S, Maruyama H, Hashimoto K (2006) Regulation of proopiomelanocortin gene transcription during single and repeated immobilization stress. Neuroendocrinology 84:21-30

Palermo F, Nabissi M, Cardinaletti G, Tibaldi E, Mosconi G, Polzonetti-Magni AM (2008) Cloning of sole proopiomelanocortin (POMC) cDNA and the effects of stocking density on POMC mRNA and growth rate in sole, Solea solea. Gen Comp Endocrinol 155:227-233

Piault R, Gasparini J, Bize P, Jenni-Eiermann S, Roulin A (2009) Pheomelanin-based coloration and the ability to cope with variation in food supply and parasitism. Am Nat 174:548-556

Pritchard LE, Turnbull AV, White A (2002) Pro-opiomelanocortin processing in the hypothalamus: impact on melanocortin signalling and obesity. J Endocrinol 172:411-421

Pulichino AM, Vallette-Kasic S, Couture C, Gauthier Y, Brue T, David M, Malpuech G, Deal C, van Vliet G, De Vroede M, Riepe FG, Partsch CJ, Sippell WG, Bergeroglu M, Atasay B, Drouin J (2003) Human and mouse TPIT gene mutations cause early onset pituitary ACTH deficiency. Genes Dev 17:711-716

Roulin A (2009) Covariation between eumelanic pigmentation and body mass only under specific conditions. Naturwissenschaften 96:375-382

Roulin A, Ducret B, Ravussin P-A, Altwegg R (2003) Female colour polymorphism covaries with reproductive strategies in the tawny owl Strix aluco. J Avian Biol 34:393-401

Roulin A, Gasparini J, Bize P, Ritschard M, Richner H (2008a) Melanin-based colourations signals strategies to cope with poor and rich environments. Behav Ecol Sociobiol 62:507-519 
Roulin A, Ducret B, Bize P, Piault R, Ravussin P-A (2008b) Régime alimentaire de la chouette hulotte Strix aluco en Suisse romande de 1986 à 2007. Nos Oiseaux 55:149-156

Rousseau K, Kauser S, Pritcahrd LE, Warhurst A, Oliver RL, Slominski A, Wei ET, Thody AJ, Tobin DJ, White A (2007) Proopiomelanocortin (POMC), the ACTH/melanocortin precursor, is secreted by human epidermal keratinocytes and melanocytes and stimulates melanogenesis. FASEB J 21:1844-1856

Sanchez VC, Goldstein J, Stuart RC, Hovanesian V, Huo L (2004) Regulation of hypothalamic prohormone convertases 1 and 2 and effects on processing of prothyrotropin-releasing hormone. J Clin Invest 114:357-369

Schallreuter KU, Kothari S, Chavan B, Spencer JD (2008) Regulation of melanogenesis-controversies and new concepts. Exp Dermatol 17:395-404

Schwartz MW, Porte D (2005) Diabetes, obesity, and the brain. Science 307:375-379

Shahjahan M, Hamabata T, Motohashi E, Doi H, Ando H (2010) Differential expression of three types of gonadotropin-releasting hormone genes during the spawning season in grass puffer Takifugu niphobles. Gen Comp Endocrinol 167:153-163

Silvers WK (1979) The coat colors of mice. Springer, New York

Slominski A (2009) Neuroendocrine activity of the melanocyte. Exp Dermatol 18:760-763

Slominski A, Wortsman J, Luger T, Paus R, Solomon S (2000) Corticotropin releasing hormone and proopiomelanocortin involvement in the cutaneous response to stress. Physiol Rev 80:979-1020

Slominski A, Tobin DJ, Shibahara S, Wortsman J (2004) Melanin pigmentation in mammalian skin and its hormonal regulation. Physiol Rev 84:1155-1228
Sturm RA (2006) A golden age of human pigmentation genetics. Trends Genet 22:464-468

Ugwu SO, Blanchard J, Door RT, Levine N, Brooks C, Hadley ME, Aickin M, Hruby VJ (1997) Skin pigmentation and pharmacokinetics of melanotan-I in humans. Biopharm Drug Dispos 18:259269

Van der Ploeg LH, Martin WJ, Howard AD, Nargund RP, Austin CP, Guan X, Drisko J, Cashen D, Sebhat I, Patchett AA, Figueroa DJ, Dilella AG, Connolly BM, Weinberg DH, Tan CP, Palyha OC, Pong S-S, MacNeil T, Rosenblum C, Vongs A, Tang R, Yu H, Sailer AW, Fong TM, Huang C, Tota MR, Chang RS, Stearns R, Tamvakopoulos C, Christ G, Drazen DL, Spar BD, Nelson RJ, MacIntyre E (2002) A role for the melanocortin 4 receptor in sexual function. Proc Natl Acad Sci USA 99:11381-11386

Walker WP, Gunn TM (2010) Shades of meaning: the pigment-type switching system as a tool for discovery. Pigment Cell Melanoma Res 23:485-495

Wessells H, Hruby VJ, Hackett J, Han G, Balse-Srinivasan P, Vanderah TW (2003) Ac-Nle-c[Asp-His-DPhe-Arg-Trp-Lys]-NH2 induces penile erection via brain and spinal melanocortin receptors. Neuroscience 118:755-762

Wilkinson CW (2006) Roles of acétylation and other post-translational modifications in melanocortin function and interactions with endorphins. Peptides 27:453-471

Yaswen L, Diehl N, Brennan MB, Hochgeschwender U (1999) Obesity in the mouse model of pro-opiomelanocortin deficiency responds to peripheral melanocortin. Nature Med 5:1066-1070 